\title{
Multi-period design and planning of closed-loop supply chains with uncertain supply and demand
}

\author{
Luis J. Zeballos ${ }^{\mathrm{a}, *}$, Carlos A. Méndez ${ }^{\mathrm{a}}$, Ana P. Barbosa-Povoa ${ }^{\mathrm{b}}$, Augusto Q. Novais ${ }^{\mathrm{c}}$ \\ a INTEC (UNL-CONICET), Güemes 3450, 3000 Santa Fe, Argentina \\ b Centre for Management Studies, Instituto Superior Técnico, Universidade de Lisboa, Lisboa, Portugal \\ ${ }^{\mathrm{c}}$ Laboratório Nacional de Energia e Geologia, Lisboa, Portugal
}

\section{A R T I C L E I N F O}

\section{Article history:}

Received 30 September 2013

Received in revised form 24 February 2014

Accepted 25 February 2014

Available online 18 March 2014

\section{Keywords:}

Closed-loop supply chains

Mathematical modeling

Multi-stage stochastic approach

\begin{abstract}
A B S T R A C T
A design and planning approach is proposed for addressing general multi-period, multi-product closedloop supply chains (CLSCs), structured as a 10-layer network (5 forward plus 5 reverse flows), with uncertain levels in the amount of raw material supplies and customer demands. The consideration of a multi-period setting leads to a multi-stage stochastic programming problem, which is handled by a mixed-integer linear programming (MILP) formulation. The effects of uncertain demand and supply on the network are considered by means of multiple scenarios, whose occurrence probabilities are assumed to be known. Several realistic supply chain requirements are taken into account, such as those related to the operational and environmental costs of different transportation modes, as well as capacity limits on production, distribution and storage. Moreover, multiple products are considered, which are grouped according to their recovery grade. The objective function minimizes the expected cost (that includes facilities, purchasing, storage, transport and emissions costs) minus the expected revenue due to the amount of products returned, from repairing and decomposition centers to the forward network. Finally, computational results are discussed and analyzed in order to demonstrate the effectiveness of the proposed approach. Due to the large size of the addressed optimization problem containing all possible scenarios for the two uncertain parameters, scenario reduction algorithms are applied to generate a representative, albeit smaller, subset of scenarios.
\end{abstract}

(c) 2014 Elsevier Ltd. All rights reserved.

\section{Introduction}

Nowadays modern industrial enterprises are operating in a business environment undergoing significant transformations that introduce new and important challenges. These involve market changes (e.g. higher competition, changeable product specifications and shorter product life cycles), new regulations for the recovery and recycling of end-use products, and the need of an increasing sustainability of the whole operation, including a reduction of environmental and social impacts. Thus, in order to ensure a profitable operation of their supply chains, enterprises need to address the ensuing challenges.

The constantly shifting and increasing customer requirements are the major challenges due to their direct effect on production systems performance (Gupta \& Maranas, 2003). Thus, as pointed out by Papageorgiou (2009), the need to account for this source of uncertainty has widely been recognized as an increasingly impor-

\footnotetext{
* Corresponding author.

E-mail address: zeballos@intec.unl.edu.ar (L.J. Zeballos).
}

tant issue. In general, different sources can be identified, such as product price and demand, production and transport costs, raw material accessibility, etc. Optimization approaches handling uncertainty considerations are then very advantageous. Nevertheless, such approaches lead to very large-scale models due to parameters with large uncertainty spaces. Reviews on optimization techniques to deal with uncertainty in the structuring and managing of corporations and their processes, can be found in Sahinidis (2004) and Li and Ierapetritou (2008).

The increasing need for remanufacturing due to resources shortage, environmental deterioration and new regulations, requires companies to organize their activities in order to explore and take full advantage of the coordination of forward and reverse material flows. Closed-loop supply chains (CLSC) extend the traditional definition of supply chains by explicitly exploring the synergy between the two flows. Thus, CLSC involves issues associated to new, enduse and remanufactured products, creating an added challenge for the design and planning problem. Therefore, practitioners and academics are paying an increasing interest to CLSCs, aiming to collect and recycle used products, with the objective of linking together environmental issues and business opportunities (Guide \& Van 